\title{
Practices and countermeasures for the treatment of black and odorous water bodies in the rural areas of Shandong Province
}

\author{
Shi Xiuhua ${ }^{1, a^{*}}$, Wu Qiong ${ }^{2, b}$ \\ ${ }^{1,2}$ School of Literature,law and Economics, Wuhan University of Science and Technology,WuHan, Hubei Province.
}

\begin{abstract}
In recent years, with the rapid development of the rural economy, while the living standards of rural residents have been greatly improved, the environmental conditions in the rural areas are not optimistic, and water pollution is one of the most important ones. Therefore, in order to improve the rural ecological environment and promote the task of water pollution control, Shandong Province has issued "the Governance Action Plan of black and odor water in rural areas of Shandong Province". This article mainly uses " the Action Plan" as a guide to analyze the current situation of rural black water bodies in Shandong Province and the current problems and related countermeasures, and follow the "comprehensiveness, applicability, economy, long-term effectiveness and safety. According to the black and odorous water problems caused by natural, technological and human factors, we will adopt comprehensive methods such as water purification, dredging, source control and pollution interception ${ }^{[1]}$ to promote the treatment of black and odorous water bodies in rural areas, solve outstanding water environment problems in rural areas, and speed up construction of beautiful and livable countryside.
\end{abstract}

\section{Analysis of the status quo of rural black and odor water body in Shandong Province}

Driven by the requirements "Action Plan for Prevention and Control of Water Pollution" regarding the nationwide implementation of urban black and odorous water treatment work, the current urban black and odorous water bodies have been effectively treated ${ }^{[2]}$. However, because Shandong Province is a large agricultural province, there are more than 70,000 villages in the province, and the black and odor water bodies in rural areas have the characteristics of wideranging, concealed and repetitive, and obvious seasonal changes, which have a greater impact on the ecological environment. It is far-reaching and has not yet been effectively governed. From June to November 2020, Shandong Province organized the investigation of black and odorous water bodies in rural areas, and took the lead in using satellite remote sensing monitoring and manual investigation to investigate all administrative villages in the province. Specifically, the main gathering areas of villagers in each administrative village appropriately extend the water bodies within 1,000 meters of the area, as well as the black and odor water that the villagers reflect strongly. The investigation found a total of 1398 black and odor water bodies in rural areas.Therefore, in order to carry out rural black and odorous water treatment, the Provincial Department of Ecology and Environment, the Provincial Department of Water Resources, the Provincial Department of Agriculture and Rural Affairs and the Provincial Department of Finance jointly issued "the Action Plan" for rural black and odorous water treatment in Shandong Province, which provided a good policy basis for the rural black and odorous water treatment.

\section{Causes of black and odorous water bodies in rural areas}

Rural black and odor water bodies can be identified based on sensory characteristics such as the smell and color of the water body. If the water body has peculiar smell or the color is obviously abnormal, it is regarded as black and odor water body. At the same time, for suspicious water bodies with controversial sensory judgments, water quality monitoring can be used to determine whether they are black or smelly. The water quality monitoring indicators include three indicators of transparency, dissolved oxygen, and ammonia nitrogen. The specific indicator thresholds are as follows:

*Corresponding author: ${ }^{\text {a. }}$ Shi Xiuhua (1968-), associate professor and Ph.D. in the School of Literature,law and Economics ,Wuhan University of Science and Technology, has been engaged in social governance research for many years. email:1716682261@qq.com

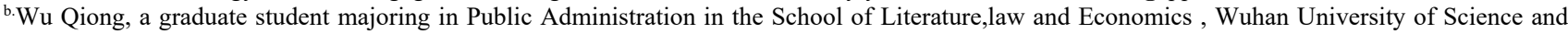
Technology. email:2719160095@qq.com 
Table 1. Water quality monitoring index.

\begin{tabular}{|c|c|}
\hline Water quality monitoring index(unit) & Index threshold \\
\hline transparency $(\mathrm{cm})$ & $<25$ \\
\hline Dissolved oxygen $(\mathrm{mg} / \mathrm{L})$ & $<2$ \\
\hline Ammonia $(\mathrm{mg} / \mathrm{L})$ & $>15$ \\
\hline
\end{tabular}

As far as the reasons for the formation of black and odor water bodies in rural areas are concerned, it can be divided into three aspects: natural, technological and human factors.

\subsection{Natural factors}

\subsubsection{The lack of oxygen in the water causes black and odor problems ${ }^{[3]}$.}

With the rapid development of the global economy, the industrial sector has continuously expanded its production scale, and the global warming climate problem has become increasingly serious with the growth of development, which poses a great threat to the normal operation of river courses and aggravates the degree of oxidation of water resources.

\subsubsection{The bottom sludge is deposited and pollutants are continuously released.}

After the pollutants enter the water, they will continuously accumulate in the bottom sludge, causing the bottom sludge to be polluted. If the amount of pollutants adsorbed by the bottom sludge reaches saturation, it will continuously release pollutants into the water body, causing more serious water pollution.

\subsection{Technical factors}

\subsubsection{The coverage of the sewage collection pipe network is poor ${ }^{[4]}$.}

A large amount of domestic sewage is discharged into rivers and other water bodies without being collected and treated. In addition, the misconnection of the pipe network is common, and the sewage will be directly discharged into the water body after the sewage pipe is wrongly connected to the rainwater pipe, causing the water body to become black and smelly.

\subsubsection{The drainage system is not sound enough.}

At present, the sewage pipes and drainage pipes in many villages and even cities in China are not separated. The sewage will be discharged into the water body along with the rainwater channel, which brings huge sewage treatment pressure to the sewage treatment plant. If the rainfall increases, the sewage treatment plant cannot treat the excess water and can only discharge it into the water body, causing pollution to the rural water environment.

\subsection{Human factors}

\subsubsection{Random dumping of garbage leads to black and odor water bodies.}

There are informal garbage dumps around some black and odorous water bodies; Some residents build kitchens and toilets along the river for convenience, and discharge pollutants directly without treatment ${ }^{[5]}$; In addition, the domestic sewage in some primary and secondary school canteens is directly discharged, and rainwater will carry pollutants into ditches and ponds continuously, thus causing the water body to be black and smelly.

\subsubsection{The industrial sector is also an important factor that seriously damages the quality of urban rivers.}

In order to effectively promote the production efficiency and scale of enterprises, a large number of toxic pollutants, such as waste gas and wastewater, are directly volatilized into the atmosphere and rivers without standardized treatment in the manufacturing process of some enterprises, causing large-scale water pollution to urban rivers.

\subsubsection{Inadequate supervision and management will affect the urban water landscape.}

In addition to the above reasons, inadequate supervision of the surrounding environment of the water body is also an important reason for the black and odor water body. In addition, due to the incomplete identification and incomplete treatment of black and odor water bodies, local inspections of new black and odor water bodies are incomplete, and some newly added black and odor water bodies require public participation and national supervision and discovery.

\subsubsection{It is difficult to guarantee funds for the treatment of black and odor water bodies.}

The comprehensive improvement of black and odor water bodies requires a lot of human and financial resources, and the financial capacity of local governments is difficult to support the advancement of the comprehensive improvement project of black and odor water bodies. Local governments have been unable to provide financial support. In addition to the impact of the COVID-19 in 2020, the funding guarantee for the normal operation of various departments is limited, which makes the treatment of black and odorous water bodies more difficult.

\section{Goals and principles of harnessing black and odorous water body in rural areas of Shandong province}

In order to implement the requirements of rural human settlements improvement, Shandong Province, guided by 
Xi Jinping's ecological civilization thought, closely combined with the requirements of rural human settlements improvement and pollution prevention and control, gradually eliminated the rivers and ponds in front of and behind the houses and the black and odorous water bodies strongly reflected by the masses in rural areas, and planned to use 3 years to complete the existing 1,398 rural black and odorous water treatment projects by 2023. The specific plan is shown in the following table:

Table2. Shandong Province Rural black and odor Water Body Treatment Task Target Table

\begin{tabular}{|c|c|c|c|c|}
\hline city & Now & $\mathbf{2 0 2 1}$ & $\mathbf{2 0 2 2}$ & $\mathbf{2 0 2 3}$ \\
\hline Jinan & 103 & 25 & 25 & 53 \\
\hline Qingdao & 82 & 20 & 20 & 42 \\
\hline Zibo & 33 & 8 & 8 & 17 \\
\hline Zaozhuang & 50 & 25 & 25 & 0 \\
\hline Dongying & 118 & 29 & 29 & 60 \\
\hline Yantai & 10 & 2 & 2 & 6 \\
\hline Weifang & 24 & 5 & 5 & 14 \\
\hline Jining & 317 & 159 & 158 & 0 \\
\hline Taian & 24 & 12 & 12 & 0 \\
\hline Weihai & 4 & 2 & 2 & 0 \\
\hline Rizhao & 25 & 5 & 5 & 15 \\
\hline Linyi & 94 & 23 & 23 & 48 \\
\hline Dezhou & 103 & 25 & 25 & 53 \\
\hline Liaocheng & 35 & 8 & 8 & 19 \\
\hline Binzhou & 138 & 33 & 34 & 71 \\
\hline Heze & 238 & 119 & 119 & 0 \\
\hline Sum & 1398 & 500 & 500 & 398 \\
\hline & & & & \\
\hline
\end{tabular}

In the treatment of black and odorous water bodies in rural areas, the principles of "comprehensiveness, applicability, economy, long-term effectiveness, and safety" must be followed. The so-called comprehensiveness means that when choosing a treatment technology, you can not only achieve water quality improvement from one aspect or rely on a single technology, but comprehensively consider the combination of various technologies to achieve the treatment of black and odorous water bodies. Adhere to adapting measures to local conditions, resolutely prevent "one size fits all", and fully integrate rural types, natural environment and economic development level and other factors to carry out governance in different areas. The so-called applicability means that different treatment technologies have different characteristics, and it is necessary to prioritize the selection of applicable technologies according to the degree of water pollution, pollution causes and different treatment stages. Economy, that is, when choosing treatment technology, a comprehensive comparison and selection of different treatment technology solutions should be carried out, and the economically feasible technology should be selected ${ }^{[6]}$. Long-term effectiveness means that when studying black and odorous water treatment countermeasures, not only the short-term effects after the implementation of the technical plan should be considered, but also the long-term water quality improvement effects and water quality stability should be paid attention to. Taking full account of the lagging rural environmental infrastructure construction in Shandong Province, a weak working foundation, and a wide range of people, a phased goal of promoting rural black and odorous water treatment is proposed. Safety is to consider the adverse effects and secondary pollution of the water environment after the implementation of the technology.

\section{Relevant measures for the treatment of rural black and odorous water bodies in Shandong province}

It is a very complicated systematic work to fundamentally treat black and odorous water bodies and prevent the black and odorous water bodies from turning back to black and repeated deterioration of water quality in rural areas. In the specific practice of black and odorous water bodies, physical, biological and chemical technologies should be organically integrated according to the specific conditions. In combination, develop highefficiency and low-consumption treatment technologies suitable for the actual conditions of Shandong Province. According to the requirements "Action Plan", in view of the existing black and odorous water bodies in the rural areas of Shandong Province, the source control, pollution interception, silt dredging and dredging were taken on the basis of a thorough analysis of the source of pollution and the causes of the black and odor from the three aspects of nature, technology and man-made. 3 measures such as water purification and targeted treatment.

\subsection{In response to the phenomenon of black and odorous water bodies in rural areas caused by human factors, adopt the method of source control and pollution interception.}

First of all, rural black and odorous water bodies can be divided into rural domestic sewage, livestock and poultry breeding sewage, aquaculture, rural domestic garbage, planting non-point source pollution, industrial sewage, and other 7 types.Scientific selection and technology are feasible.Economic and reasonable treatment methods to eliminate external source pollution.

Secondly, the government needs to strengthen the investment in black and odorous water treatment ${ }^{[7]}$, incorporate rural black and odorous water treatment into the important content of rural ecological revitalization work, encourage and guide social capital to participate in rural black and odorous water treatment, and actively seek financial support from higher authorities to ensure the source of funds for black and odorous water bodies.

Finally, in order to ensure the effectiveness of governance, relevant provincial departments and units need to strengthen inspections and regular inspections in the process of carrying out specific supervision work, and it is strictly forbidden for enterprises to surreptitiously discharge and leak discharge. 


\subsection{In view of the black and odorous water phenomenon in rural areas caused by technical problems, the method of removing the silt and then dredging.}

In view of the current remediation path of black and odor water bodies in rural areas, we must start with the investigation of pollution sources and continuously strengthen the protection of water bodies. Therefore, from a feasible point of view, rationally construct river basin pollution interception projects, establish a pipe network connection function, run through the sewage interception work upstream and downstream of the river, and promote the centralized collection of rural domestic waste water, thereby promoting the efficiency of waste water treatment.

For water bodies that still have black and odor after adopting source control and interception measures to eliminate external source pollution, internal source treatment shall be carried out. Comprehensively evaluate the water quality and bottom mud conditions of rural black and odorous water bodies, and scientifically formulate dredging and dredging plans.

\subsection{Because of the phenomenon of black and odor water bodies in rural areas caused by natural factors, water purification methods should be adopted.}

In terms of water purification, areas with better economic conditions can carry out ecological care in time, and at the same time reconstruct the water ecosystem and improve the self-purification capacity of water bodies. For villages that are too scattered and ecologically fragile, the natural shoreline of rural water bodies should be maintained on the premise of meeting the requirements of flood control and drainage. Taking into account the actual conditions of the region's economic conditions, topography, recent planning, etc., adopt scientific methods to reconstruct the water ecosystem and enhance the self-purification capacity of water bodies.

Strictly control water transfer and pollution flushing on the grounds of restoring hydrodynamic force, so as to ensure the landing of treatment projects. All localities have formulated engineering schemes one by one, implemented engineering investment, formulated implementation plans, and established dispatching ledgers. In the use of funds, in strict accordance with the provisions of the measures for the administration of project funds, make overall plans for the construction and management, and bring into play economic, social and environmental benefits.

\section{Conclusion}

The treatment of black and odor water bodies in rural areas itself is a systematic and complicated process ${ }^{[8]}$. In addition, the pollution of rivers in Shandong Province is relatively serious and the distribution is relatively scattered. Therefore, the phenomenon of "to treat the symptoms rather than getting to the root of the problem" should be avoided. In the specific implementation process, it is necessary to follow the requirements "the Action Plan" and learn from the successful governance experience of other provinces and cities, and grasp the principles of adapting measures to local conditions and timeliness, so that the restoration of black and odorous water bodies can be carried out for a long time and reach the maximum Good results.

\section{Acknowledgments}

This article was supported by Hubei NPO Research Cent er (Project Number: HBNPO2020YB01)

\section{References}

1. Chen,J.,L.(2021).Design Points for Comprehensive Treatment of Urban Black and Odorous Water Bodies.Low Carbon World,11:73-74.

2. Zhao,Y.C.,Li,Y.C.,(2020)Study on the Causes and Treatment of Black and Odor Water in Rural Areas of Anhui Province.Environment and Sustainable Development,45:154-157.

3. Li,X.M.(2016)Study on the Cause of the Black Odor Water Body and Its Comprehensive Treatment.Chemical Intermediate, 8:85-86.

4. Ma,T.,Liang,J.B.(2020)The Causes of Urban Black and Odorous Water Bodies and Treatment Methods.Technology and Application,12:109-111

5. Wu,S.X.,Lu,D.L.,Xia,Y.H.(2020)Current Situation and Counter Measure of Black and Odorous Water in Guizhou Province.Environment and Development,32:63-64+66.

6. Hu,H.Y.,Sun,Y.,Xi,J.Y.,Zhao,T.T.(2015)Treatment and Water Quality Improvement Technology of Black-and-Malodorous Water Body in Urban Area.Environmental protection,43:24-26.

7. Sun,Z.L.(2021)Comprehensive Treatment and Long-term Management of Urban Black and Odorous Water Bodies.Anhui Architecture,28:8586.

8. Cheng,Q.L.,He,Y.,Huang,M.S.,Tong,M.(2011)The Discussion on the Treatment Methods of Urban Malodorous River.Shanghai Chemical Industry,36:25-31. 